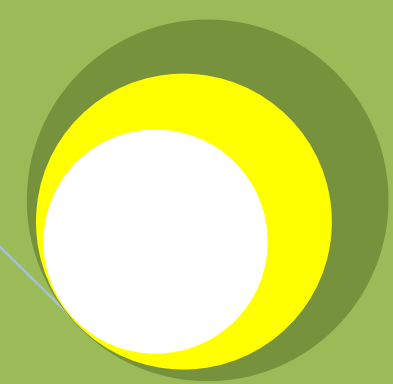

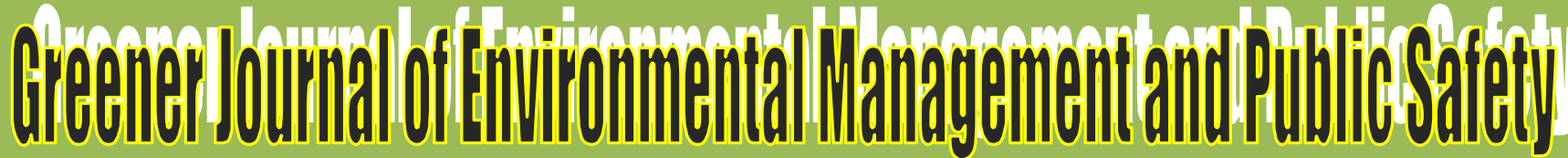

ISSN: 2354-2276

\title{
The Study of the $\mathrm{C} / \mathrm{N}$ Ratio in the Domestic Biogas Usable Wastes: A Case Study of Irhambi/Katana
}

By

Chanceline Bahati Mutalemba Etienne Mugaruka Mashimango Godefroid Kubisibwa Mulengera Soleil Habamungu Shalukoma 


\title{
The Study of the $\mathrm{C} / \mathrm{N}$ Ratio in the Domestic Biogas Usable Wastes: A Case Study of Irhambi/Katana
}

\section{Chanceline Bahati Mutalemba1', Etienne Mugaruka Mashimango*2, Godefroid Kubisibwa Mulengera ${ }^{1}$, Soleil Habamungu Shalukoma ${ }^{3}$}

\author{
${ }^{1}$ Researcher in Natural sciences Research Center (CRSN-Lwiro in DRCongo), Environment Department. \\ ${ }^{2}$ Assistant in CEPROMAD University (Bukavu DRCongo). \\ ${ }^{3}$ Researcher in Natural sciences Research Center (CRSN-Lwiro in DRCongo), Biology Department.
}

*Corresponding Author's Email: stevemugaruka@gmail.com; mugarukae@yahoo.fr, Tel: 0853541124; 0992646436

\begin{abstract}
This article is on the study of the $\mathrm{C} / \mathrm{N}$ ratio in the domestic biogas usable wastes. The global objective was to detect the concentration of nitrogen and carbon, the determination of the ratio as well as their connection in the different types of biogas usable wastes. The authors took samples, tested and studied it in laboratories in Lwiro and others were done in the National Program of Biogas for Burkina-Faso 2005. To observe the concentration and connection, the correlation test wad used. The Kjeldhal method and the statistic one have allowed attending results. The test for the animal and human wastes gave a correlation of 0.362 and 0.95 respectively. It showed however no correlation for the agricultural wastes with 24, because this numeral wasn't in the space of -1 and 1 . The average $\mathrm{C} / \mathrm{N}$ ratio was is 24, 9 for first type and 74 for the second type of wastes.
\end{abstract}

Keywords: $\mathrm{C} / \mathrm{N}$ ratio, organic waste, domestic biogas.

Usable wastes: means wastes agreed in an easy and rapid production of domestic biogas.

$\mathbf{P}=$ probability, $\mathrm{E}=$ mathematics expectancy.

\section{INTRODUCTION}

The environmental protection and waste management constitute a preoccupation for the national and the international community. On many farms, the basic composting ingredients are manure generated on the farm and bedding. Each type of manure has its own physical, chemical and biological characteristics. Cattle and horses manures, when mixed with bedding possess good qualities for composting. Swine manure, which is very wet and usually not mixed with bedding material, must be mixed with straw or similar raw materials. Poultry also must be blended with carbonaceous materials; those low in nitrogen are preferred, such as sawdust or straw (Dougherty, 1999). Some live in symbiotic relationships with other life forms, including termites, ruminants and cultivated crops, other sources of methane, the principal component of natural gas include landfill gas, biogas, and methane hydrate (University of Minnesota, 2011). The nitrogen is a chemistry element of the pnictogen family of $\mathrm{N}$ symbol (from latine nitrogenium) and of the atomic number 7 . The " minerals " containing the nitrogen are principally the nitrates : nitrate of potassium $\mathrm{KNO}_{3}$ (constituent of saltpeter) or « niter » which was serving in the former time to produce explosive powders; nitrate of sodium $\mathrm{NaNO}_{3}$ (constituent of saltpeter of Chill). Antoine Lavoisier has chosen the name (azote) nitrogen, composed of a- (privative) of the greecque radical $\zeta \omega \omega_{-}$, " alive " and means therefore "privated of life ", because contrary to oxygen, it doesn't maintain the life of animals. The English term nitrogen has conserved that root for pointing out "azote" in French (David, 2009). The nitrogen has 16 isotopes known by the mass number varing from 10 to 25 , as well as one nuclear isomer, $11 \mathrm{mN}$. Two of them are stable and present in the nature, the nitrogen $14(14 \mathrm{~N})$ and the nitrogen $15(15 \mathrm{~N})$, the first representing almost the totality of the present nitrogen (99. 64\%) (Beatriz et al., 2008). The carbon is a chemical element of the cristalogens family, of $C$ symbol, of atomic number 6 and of atomic mass 12, 0107 . The name carbon comes from latine carbo, carbonis meaning " coal » (Cesar, 1865). The principal organic corps of carbon is hydrocarbon, the molecules associating with carbon and hydrogen. The hydrocarbons are classed in three families: * the alkanes where the carbon forms connections sp3 (simple), *the alkenes where at least one carbon forms the connections « double " (carbon sp2). *The alkynes where at least one carbon forms connections " triple » (carbon sp) (Greenwood and Earnwhaw, 1994). In the exploitation and today usages, the fizzy nitrogen or diazote is generally obtained by liquefaction of the air, in which it is a principal corps with a concentration of $78.06 \%$ in volume and of $75.5 \%$ in mass. The world production is around 150 millions of tons per year 
(Greenwood and Earnwhaw, 2003). The protoxide of nitrogen (hilarant gas) is used as anesthetic; the ammoniac $\mathrm{NH} 3$, used as raw material for the production of polymers, of explosives, of fertilizer, or as fluid refrigerant in certain industrial installations; combustibles; explosives; propulser gas for aerosol bombs (N2O) or aerographs; conservator; nitrogenize of sodium, used for swelling immediately the swellable cushions of security (of a car for example) in case of chock (Paul et al., 2004). After this introduction it is better to delimit our problems in summarizing it in this question: what is the Carbon/Nitrogen ratio for each species of the studied wastes? What is the correlation between carbon and nitrogen in each type of wastes? As an answer to our problems, the power of the nitrogen and carbon is located in the carbon/nitrogen ratio which must be found between 20 and 30 for good biogas production. We realized that the animal and household/human wastes are preferable and well indicated in domestic digestors than the agricultural one, the relation is found in the need of carbon 25 to 30 more than the nitrogen as our study showed. The ideal proportion of $\mathrm{C} / \mathrm{N}$ ratio of this type of wastes should be between 25 to 30. Otherwise the process can be disturbed and bring the domestic biogas production to failure (National Program of Biogas for Burkina-Faso, 2005). The nitrogen is present in the organic and inorganic corps. It is one of the components of numerous minerals and the air. The nitrogen is a gas (Haynes, 2011).

\section{STUDY AREA}

The groupment of Irhambi-Katana is located on the North shore of Kivu Lake between $2^{\circ}$ and $2^{\circ} 30^{\prime}$ of South latitude and $28^{\circ} 30^{\prime}$ and of $29^{\circ}$ of East longitude (BALUKU, 1997). It is included in Kabare territory, South-Kivu in Democratic Republic of Congo and is found at $50 \mathrm{Km}$ in the North of Bukavu town. It is composed by six towns namely: Mwanda, Kahungu, Kabushwa, Mabingu, Kabamba and Kajuchu. With his surface of $189,5 \mathrm{Km}^{2}$, it is limited to the North by the Nyabarongo river which separates from the territory of Kalehe, to the South by Bugorhe groupment, to the East by Kivu lake, to the west by Kahuzi-Biega National park. The groupment of Irhambi/Katana is among the high lands of the east of Congo. His relief is globally marked by tectonic movements which have affected the eastern Africa. It is presented by a cut up shore which is characteristic of the narrow bays, the peninsulas (as Kajuchu). From East to West, we note the presence of three alleviates which more or less stacked. They correspond to ancient rift valley bottoms respectively to $1470 \mathrm{~m}$ in Cibale towards Mwanda (shore of the lake) at $1580 \mathrm{~m}$ in commercial centre of Katana, for passing at $2074 \mathrm{~m}$ in Chombo (Kahungu) and at more than $2200 \mathrm{~m}$ of Tshibati. The vegetation is principally composed by the banana fields Musa spp of some small islands of Eucalyptus spp, Ficus spp, Erythrina abyssinica etc., the pasturage savanna is dominated by Hyparhenia kind. In the swamp and lakeside the savanna is composed by the Cyperus latifolius and Phragmites mauritianus, Bridelia micranta, Albizia ssp, Alangium chinense. The major constraint of the community is tied up to the great population, with a human density around 575, 4 habitants $/ \mathrm{km}^{2}$.

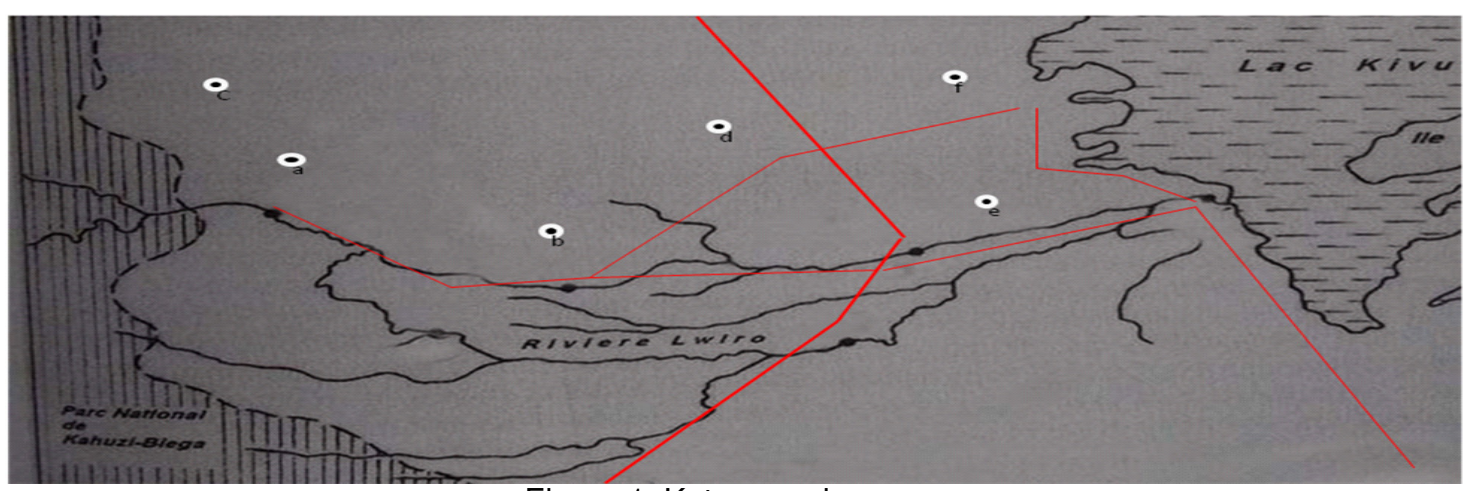

Figure 1: Katana region map

Legend: Data collection Sites

Raod sections which cross the region

National road No5 linking Bukavu to Goma

a: Kabushwa b: Kahungu c: Mabingu d: Kabamba e: Mwanda f: Kajuchu. 


\section{MATERALS AND METHODS}

The Kjeldhal method and the statistic one have allowed us to harvest samples and detect the connections existing between the different types of the wastes for biogas. They consisted in harvesting samples of wastes on the ground, and among small farmers, for catching at the end some informations on the quantity of nitrogen and/or carbon contained in it, after the analysis in the laboratories. The Kjeldhal method helped in measuring the $\mathrm{C} / \mathrm{N}$ ratio. 16 species (among which 7 for the animal wastes, 6 for agricultural wastes and 3 for the household wastes) were studied in this groupment and somewhere else in south-Kivu province. But let's say that some other species were found somewhere else in the region. For treating the already classified data, we used the correlation test after the laboratory work. The materials we used are: phial, sulphuric acid, potassium sulfate, copper sulfate, grains pumice stone, distilled water, distillation assemblage. We proceeded by mineralization of the corps for passing from organic nitrogen to the mineral nitrogen. We deducted the molecule in oxyding it and boiling with the concentrated sulphuric acid, in the presence of catalyst: the carbon was taken as dioxide of carbon and, hydrogen as water. The nitrogen stayed in solution as ammonium ion to be evaluated in \%.

\section{RESULTS}

According to the inquiries and the found results in laboratories for the samples of the manure of cow, sheep (goat), poultry, pig, horse, duck and elephant; we have regrouped those samples into this table as following:

Table 1: The Animal Wastes

\begin{tabular}{|l|l|l|l|l|}
\hline $\mathbf{N}^{\circ}$ & Animal & Nitrogen & Carbon & Ratio Carbon Nitrogen \\
\hline 01 & Cow & 1.66 & 30 & 18 \\
\hline 02 & Sheep (Goat) & 3.80 & 83.6 & 22 \\
\hline 03 & Poultry & 6.55 & 97.5 & 15 \\
\hline 04 & Pig & 3.8 & 76 & 20 \\
\hline 05 & Horse & 2.3 & 133.4 & 58 \\
\hline 06 & Duck & 2 & 54 & 27 \\
\hline 07 & Elephant & 1.3 & 60 & 56 \\
\hline
\end{tabular}

Source : Laboratory

With these datas, we have wanted to check the relations which exist between the elements found for nitrogen and the one for carbon which are useful in biogas production. According to the equiprobability, each couple has $1 / 7$ of chance to appear.

\section{The study of the value of $X$ (Nitrogen)}

For $x=1.66, P(x=1.66)=1 / 7 ; E(x)=1.66 \times 1 / 7=0.23 ; E\left(x^{2}\right)=$ ?

$\mathrm{X}^{2}=(1.66)^{2}=2.75 ; E\left(x^{2}\right)=2.75 \times 1 / 7=0.39$.

For $\mathrm{X}=3.8, \mathrm{P}(3.8)=2 / 7 ; \mathrm{E}(\mathrm{x})=1.08 ; \mathrm{E}\left(\mathrm{x}^{2}\right)=4.12$

For $x=6.55, P(x=6.55)=1 / 7 ; E(x)=0.93 ; E\left(x^{2}\right)=6.12$

For $x=2.3, P(x=2.3)=1 / 7 ; E(x)=0.32 ; E\left(x^{2}\right)=0.75$

For $x=2, P(x=2)=1 / 7 ; E(x)=0.28 ; E\left(x^{2}\right)=0.57$

For $\mathrm{x}=1.3, \mathrm{P}(\mathrm{x}=1.3)=1 / 7 ; \mathrm{E}(\mathrm{x})=0.18 ; \mathrm{E}\left(\mathrm{x}^{2}\right)=0.24$.

$\mathrm{E}(\mathrm{X})=\sum_{i=1}^{7}(E x i)=3.02,\left(\mathrm{E}(\mathrm{x})^{2}\right)=(3.02)^{2}=9.12, \mathrm{E}\left(\mathrm{X}^{2}\right)=\sum_{i=1}^{7}\left(E\left(x i^{2}\right)\right)=12.19$

Variance of $X=E\left(X^{2}\right)-[E(X)]^{2}=12.19-9.12=3.07$

\section{The study of the value of $Y$ (carbon)}

For $\mathrm{y}=30, \mathrm{P}(\mathrm{x}=30)=1 / 7 ; \mathrm{E}(\mathrm{y})=30 \times 1 / 7=4.28, \mathrm{y}^{2}=900 ; \mathrm{E}\left(\mathrm{y}^{2}\right)=900 \times 1 / 7=128.57$

For $\mathrm{y}=83.6, \mathrm{P}(\mathrm{y}=83.6)=1 / 7 ; \mathrm{E}(\mathrm{y})=11.94 ; \mathrm{E}\left(\mathrm{y}^{2}\right)=998.42$

For $\mathrm{y}=97.5, \mathrm{P}(\mathrm{y}=97.5)=1 / 7 ; E(\mathrm{y})=13.92 ; E\left(\mathrm{y}^{2}\right)=1358.03$

For $\mathrm{y}=76, \mathrm{P}(\mathrm{y}=76)=1 / 7 ; E(\mathrm{y})=10.85 ; E\left(\mathrm{y}^{2}\right)=825.14$

For $\mathrm{y}=133.4, \mathrm{P}(\mathrm{y}=133.14)=1 / 7 ; \mathrm{E}(\mathrm{y})=19.05 ; \mathrm{E}\left(\mathrm{y}^{2}\right)=2542.22$

For $\mathrm{y}=54, P(y=54)=1 / 7 ; E(y)=7.71 ; E\left(y^{2}\right)=416.57$

For $y=60, P(y=60)=1 / 7 ; E(y)=8.57 ; E\left(y^{2}\right)=514.28$. 
$\mathrm{E}(\mathrm{Y})=\sum_{i=1}^{7} E(y i)=76.32 ; \mathrm{E}\left(\mathrm{Y}^{2}\right)=\sum_{i=1}^{7}\left(E\left(y^{2}\right)\right)=6783.23$

Variance of $Y=E\left(y^{2}\right)-[E(y i)]^{2}=6783.23-5230.18=1553.05$

For measuring the relation which exists between the two variables Nitrogen and carbon, it is better to calculate the covariance or the possible correlation.

Covariance $(X, Y)=E(X Y)-E(X) E(Y)$

$\mathrm{E}(\mathrm{XY})=$ ?

Table 2: The calculation of (XY) from the table 1.

\begin{tabular}{|l|l|l|l|}
\hline animal & $\mathbf{X}$ & $\mathbf{Y}$ & $\mathbf{X Y}$ \\
\hline Cow & 1.66 & 30 & 49.8 \\
\hline Sheep & 3.8 & 83.6 & 317.68 \\
\hline Poultry & 6.55 & 97.5 & 638.62 \\
\hline Pig & 3.8 & 76 & 288.8 \\
\hline Horse & 2.3 & 133.4 & 306.82 \\
\hline Duck & 2 & 54 & 108 \\
\hline Elephant & 1.3 & 60 & 78 \\
\hline
\end{tabular}

Source : Calculations

For $x y=49.8, P(x y=49.8)=1 / 7 ; E(x y)=49.8 \times 1 / 7=7.11$

For $x y=317.68, P(x y=317.68)=1 / 7 ; E(x y)=45.38$

For $x y=638.62, P(x y=638.62)=1 / 7 ; E(x y)=91.23$

For $x y=288.8, P(x y=288.8)=1 / 7 ; E(x y=41.25$

For $x y=306.82, P(x y=306.82)=1 / 7 ; E(x y)=43.83$

For $x y=108, P(x y=108)=1 / 7 ; E(x y)=15.42$

For $x y=78, P(x y=78) ; E(x y)=11.14$.

$E(X Y)=\sum_{i=1}^{7}((x i y i))=255.36$

Then Covariance $(X Y)=255.36-(3.02)(76.32)=25$

We realize that these two random variables Nitrogen and Carbon are not independents because their covariance is not 0 . The variation between $X$ and $Y$ is of 25 units.

\section{Calculation of correlation coefficient ( ()}

This coefficient of correlation will help us measure the degree of the relation which exists between nitrogen and carbon. That ratio must be in the space of -1 and 1 .

If $\phi=-1$ therefore the relation is total but negative, if $\phi=0$ therefore the relation doesn't exist, if $\phi=1$ therefore the relation is total and positive.

$\Phi=\frac{\operatorname{Cov}(X Y)}{\sqrt{\operatorname{Var}(X) \operatorname{Var}(Y)}}=\frac{25}{\sqrt{3.07 X 1553.05}}=\frac{25}{69.04}=0.362$

Interpretation: The relation exist between these two variables Nitrogen and carbon.

When one increases; of 25, the other increases however; of 0,36 units.

This relation is therefore weak and positive because our coefficient of correlation is located between 0 and 0,5 .

\section{Ratio Carbon/Nitrogen (C/N)}

The organic material contains many chemical elements among; the principal elements are carbon $(C)$, hydrogen $(H)$, Nitrogen $(N)$, phosphore $(P)$, sulphur $(S)$. the ratio Carbon/Nitrogen is an important index for evaluating the capacity of materials to decompose. Generally, the microbes' generator of biogas has the need of carbon twenty 
five to thirty more than the nitrogen. Consequently, the optimal ratio of $\mathrm{C} / \mathrm{N}$ of raw materials is 25 to 30 . The raw materials with a $\mathrm{C} / \mathrm{N}$ ratio inferior will begin the fermentation rapidly than the one of a high $\mathrm{C} / \mathrm{N}$ ratio. Moreover, these last ratios are sensitive to acidity and can bring the fermentation to failure.

The $\mathrm{C} / \mathrm{N}$ ratio of the manure for pig and livestock is suitable, while the one of human wastes and the excrements of hens are inferior for effective digestion. The ratio $\mathrm{C} / \mathrm{N}$ of the cool vegetation is high and that ratio becomes very high with old vegetation, consequently those materials could be mixed in the exact proportions for beginning the fermentation process and increase the biogas production. The favorable $\mathrm{C} / \mathrm{N}$ ratio for generating biogas is between 20 and 30 .

Table 3: The Household or human wastes

\begin{tabular}{|l|l|l|l|l|}
\hline $\mathrm{N}^{\circ}$ & Description & Nitrogen & Carbon & $\mathrm{C} / \mathrm{N}$ \\
\hline & (source of raw material) & $(\%$ dry weight) & $(\%$ dry weight) & (ratio) \\
\hline 1 & Poudrette (night soil) & 6.00 & 48.00 & $8-75$ \\
\hline 2 & Carillon de pomme de terre & 1.50 & 37.50 & 25 \\
\hline 3 & Déchets de cuisine & 32.50 & 62.5 & 25 \\
\hline
\end{tabular}

Source : Laboratory

The $\mathrm{C} / \mathrm{N}$ average ratio for the human and animal wastes is $30,85+19 / 2=24,9$.

After the animal waste, let's focus on household and human waste too.

\section{a. The study of the value of $X$}

For $X=6, p(x=6)=1 / 3, E(x)=6 x 1 / 3=2, x^{2}=6^{2}=36 ; E\left(x^{2}\right)=36 x 1 / 3=12$

For $x=1.5, p(x=1.5)=1 / 3, E(x)=1.5 x 1 / 3=0.5 ; x^{2}=(1.5)^{2}=2.25, E\left(x^{2}\right)=2.25 \times 1 / 3=0.75$

For $x=32.5, p(x=32.5)=1 / 3, E(x)=32.5 x 1 / 3=10.83 ; x^{2}=(32.5)^{2}=1056.25, E\left(x^{2}\right)=1056,25 \times 1 / 3=352$

Variance of $X=E\left(X^{2}\right)-[E(X)]^{2}$ or $E(X)=\sum(E x i)=13.33,[E(X)]^{2}=(13.33)^{2}=177.69$

$\mathrm{E}\left(\mathrm{X}^{2}\right)=\sum_{i=1}^{6}\left(E\left(X^{2}\right)\right)=364.75$ Then, Variance $(X)=364.75-177.69=187.06$

\section{b. The study of the values of $Y$}

For $y=48, p(y=48)=1 / 3, E(y)=48 x 1 / 3=16, x^{2}=(48)^{2}=2304 ; E\left(y^{2}\right)=2304 \times 1 / 3=768$

For $y=37.5, p(y=37.5)=1 / 3, E(y)=37.5 \times 1 / 3=12.5, x^{2}=(37.5)^{2}=1406.25, E\left(y^{2}\right)=1406.25 \times 1 / 3=468.75$

For $\mathrm{y}=62.5, \mathrm{p}(\mathrm{y}=62.5)=1 / 3, E(\mathrm{y})=62.5 \times 1 / 3=20.8, \mathrm{y}^{2}=(62.5)^{2}=3906.25, E\left(\mathrm{y}^{2}\right)=3906.25 \times 1 / 3=1302$

Variance of $\mathrm{Y}=\mathrm{E}\left(\mathrm{Y}^{2}\right) \quad-(\mathrm{E}(\mathrm{y})) \quad 2 \quad$ while $\quad \mathrm{E}(\mathrm{Y})=\sum_{i=1}^{6}(E y i)=49.3 ; \quad(\mathrm{E}(\mathrm{y}))^{2}=(49.3)^{2}=2430.49 \quad \mathrm{E}\left(\mathrm{y}^{2}\right)=$

$\sum_{i=1}^{6}\left(E\left(y i^{2}\right)\right)=2538.75$

Then, the Variance $Y=2538.75-2430.49=108.26$

Let's calculate the covariance for seeing the correlation or connection between $X$ and $Y$. Covariance $(X Y)=$ $E(X Y)-E(X) \cdot E(Y)$

Table 4: The calculation of $X Y$ from the table 3.

\begin{tabular}{|l|l|l|l|}
\hline Description & Nitrogen $(\mathrm{X})$ & Carbon $(\mathrm{Y})$ & $(\mathrm{XY})$ \\
\hline poudrette & 6 & 48 & 288 \\
\hline Potato wastes & 1.5 & 37.5 & 56.25 \\
\hline KITCHEN WASTE & 32.5 & 62.5 & 2031.25 \\
\hline
\end{tabular}

Source: calculations

For $x y=288, p(x y=288)=1 / 3, E(x y)=288 x 1 / 3=96$

For $x y=56.25, p(x y=56.25)=1 / 3, E(x y)=56.25 \times 1 / 3=18.75$

For $x y=2031.25, p(x y=2031.25)=1 / 3, E(x y)=2031.25 \times 1 / 3=677$ 
$\mathrm{E}(\mathrm{XY})=\sum_{i=1}^{3} E(X i Y i)=791.75$

Covariance $(X Y)=(791.75)-(13.33) .(49.3)=134.58 \approx 135$

We notice that those two random variables Nitrogen and Carbon are not independent because their covariance is not 0 . The variation between $X$ and $Y$ is therefore 135 units. Let's calculate the coefficient of correlation:

$\Phi=\frac{\operatorname{Cov}(X Y)}{\sqrt{\operatorname{Var}(X) \cdot \operatorname{Var}(Y)}}=\frac{135}{\sqrt{187.06 \times 108.26}}=\frac{135}{\sqrt{20251.1156}}=\frac{135}{142.3}=0.95$

Interpretation: the relation exists between those two variables Nitrogen and carbon.

The intensity of their connection is 0.95 units. This correlation is strong and positive because the coefficient of correlation is located between 0.5 and 1 (Cohen, 1988). The fact that those two variables are strongly correlated doesn't demonstrate that there is a causality relation existing between the two (Michel, 2001).

Table 5: The Grain or agricultural wastes

\begin{tabular}{|l|l|l|l|l|}
\hline $\mathrm{N}^{\circ}$ & Description & Nitrogen & Carbon & $\mathrm{C} / \mathrm{N}$ \\
\hline & (source of raw material) & $(\%$ dry weight ) & $(\%$ dry weight) & (ratio) \\
\hline 1 & Young grass & 4.00 & 48.00 & 12 \\
\hline 2 & Straw of Wheat & 0.50 & 60.00 & 120 \\
\hline 3 & Straw of Rice & 30.30 & 18.00 & 60 \\
\hline 4 & Stalk and Maize leaves & 41.00 & 55.00 & 55 \\
\hline 5 & Other leaves & 51.50 & 75.00 & 50 \\
\hline 6 & Sugar cane & 0.30 & 45.00 & 150 \\
\hline
\end{tabular}

Source: Laboratory

The $\mathrm{C} / \mathrm{N}$ average ratio is for agricultural waste is: $447 / 6=74$. At the end, it is important to check the relation that exists in the other type of waste category.

\section{The study of the values of $X$ (Nitrogen)}

For $x=4, p(x=4)=1 / 6, E(x)=4 x 1 / 6=0.67 ; x^{2}=\left(4^{2}\right)=16, E\left(x^{2}\right)=16 \times 1 / 6=2.7$

For $x=0.5, p(x=0.5), E(x)=0.5 x 1 / 6=0.08 ; x^{2}=(0.5)^{2}=0.25, E\left(x^{2}\right)=0.25 \times 1 / 6=0.04$

For $x=30.3, p(x=30.3)=1 / 6, E(x)=30.3 \times 1 / 6=5.05 ; x^{2}=(30.3)^{2}=918.09, E\left(x^{2}\right)=918.09 \times 1 / 6=153.02$

For $x=41, p(x=41)=1 / 6, E(x)=41 x 1 / 6=6.8 ; x^{2}=(41)^{2}=1681, E\left(x^{2}\right)=1681 \times 1 / 6=280$

For $x=51.5, p(x=51.5) 1 / 6, E(x)=51.5 x 1 / 6=8.58 ; x^{2}=(51.5)^{2}=2652.25, E\left(x^{2}\right)=2652.25 \times 1 / 6=442.04$

For $x=0.30, p(x=0.30)=1 / 6, E(x)=0.3 x 1 / 6=0.05 ; x^{2}=(0.3)^{2}=0.09, E\left(x^{2}\right)=0.09 x 1 / 6=0.015$

Variance $(X)=E(X) \quad-\quad(E(X))^{2} ; \quad E(X)=\sum_{i=1}^{6}($ Exi $)=21.23, \quad(E(X))^{2}=\quad(21.23)^{2}=450.71 \quad$ and $\quad E\left(X^{2}\right)$

$=\sum_{i=1}^{6}\left(E\left(x i^{2}\right)\right)=877.81$

Then Variance $(X)=877.81-450.71=427.1$

\section{A. The study of the values of $\mathrm{Y}$ (carbon)}

For $y=48, p(y=48)=1 / 6, E(y)=48 \times 1 / 6=8 ; y^{2}=(48)^{2}=2304, E\left(y^{2}\right)=2304 \times 1 / 6=384$

For $\mathrm{y}=60, \mathrm{p}(\mathrm{y}=60)=1 / 6, E(\mathrm{y})=60 \times 1 / 6=10 ; \mathrm{y}^{2}=(60)^{2}=3600, E\left(\mathrm{y}^{2}\right)=3600 \times 1 / 6=600$

For $y=18, p(y=18)=1 / 6, E(y)=18 \times 1 / 6=3 ; y^{2}=(18)^{2}=324, E\left(y^{2}\right)=324 \times 1 / 6=54$

For $y=55, P(y=55)=1 / 6, E(y)=55 \times 1 / 6=9.17 ; y^{2}=(55)^{2}=3025, E\left(y^{2}\right)=3025 \times 1 / 6=504.17$

For $y=75, p(y=75)=1 / 6, E(y)=75 \times 1 / 6=12.5 ; y^{2}=(75)^{2}=5625, E\left(y^{2}\right)=5625 \times 1 / 6=937.5$

For $y=45, p(y=45)=1 / 6, E(y)=45 \times 1 / 6=7.5 ; y^{2}=(45)^{2}=2025, E\left(y^{2}\right)=2025 \times 1 / 6=337.5$ 
Variance $\mathrm{Y}=\mathrm{E}\left(\mathrm{Y}^{2}\right)-(\mathrm{E}(\mathrm{yi}))^{2}$ Or $\mathrm{E}(\mathrm{Y})=\sum_{i=1}^{6} E(y i)=50.17, \quad(\mathrm{E}(\mathrm{Y}))^{2}=(50.17)^{2}=2517 \quad$ and $\quad \mathrm{E}\left(\mathrm{Y}^{2}\right)=$ $\sum\left(E\left(y^{2}\right)\right)=2817.17$

Then Variance of $Y=2817.17-2517=0.029$

For measuring the relation between Nitrogen $(X)$ and Carbon $(Y)$ in the agricultural wastes, the covariance or the possible connection is calculated.

Covariance $(X Y)=E(X Y)-E(X) . E(Y)$

Table 6: The calculation of $X Y$ from the table 5.

\begin{tabular}{|l|l|l|l|}
\hline Description & Nitrogen $(\mathrm{X})$ & Carbon $(\mathrm{Y})$ & $(\mathrm{XY})$ \\
\hline Young grass & 4 & 48 & 192 \\
\hline Straw of Wheat & 0.5 & 60 & 30 \\
\hline Straw of Rice & 30.3 & 18 & 545.4 \\
\hline Stalk and Maize leaves & 41 & 55 & 2255 \\
\hline Other leaves & 51.5 & 75 & 3862.5 \\
\hline Sugar cane & 0.3 & 45 & 13.5 \\
\hline
\end{tabular}

Source : Our inquiries

For $x y=192, p(x y=192)=1 / 6, E(x y)=192 x 1 / 6=32$

For $x y=30, p(x y=30)=1 / 6, E(x y)=30 x 1 / 6=5$

For $x y=545.4, p(x y=545.4)=1 / 6, E(x y)=545.4 x 1 / 6=90.9$

For $x y=2255, p(x y=2255)=1 / 6, E(x y)=2255 \times 1 / 6=375.83$

For $x y=3862.5, p(x y=3862.5)=1 / 6, E(x y)=3862.5 \times 1 / 6=643.75$

For $x y=13.5, p(x y=13.5)=1 / 6, E(x y)=13.5 \times 1 / 6=2.25$

Covariance $(X Y)=E(X Y)-E(X) \cdot E(Y)$ Or $E(X Y)=\sum_{i=1}^{6} E(X i Y i)=1149.73$

Covariance $(X Y)=1149.73-(21.23) .(50.17)=84.62 \approx 85$

It is realized that the covariance exist between these two variables $\mathrm{X}$ and $\mathrm{Y}$, and it is Positive. We calculate finally the Coefficient of Correlation:

$\Phi=\frac{\text { Co } \operatorname{var} \text { iance }(X Y)}{\sqrt{\text { Variance }(X) \text {.Variance }(Y)}}=\frac{85}{\sqrt{427.1 X 0.029}}=\frac{85}{3.52}=24$

Interpretation: In this wastes category, the correlation doesn't exist between these two variables. Therefore, Nitrogen and carbon are not logically linked in production of biogas when using the agricultural or grain wastes. Their coefficient of correlation doesn't figure in the space -1 and 1 . This means that these two variables are not correlated. The result found was 24.9 average $\mathrm{C} / \mathrm{N}$ ratio for the animal and holdhouse or human wastes. Their correlations exist and are respectively of 0.362 and 0.95 with the average $\mathrm{C} / \mathrm{N}$ ratio of 24.9. It is however inexisting for the agricultural wastes with the correlation of 24 and the average $\mathrm{C} / \mathrm{N}$ ratio is 74.5 . This showed clearly that the agricultural type of wastes is not indicated for the domestic biodigestor to produce the best quality of biogas and ensure its best production process.

\section{DISCUSSION}

The $\mathrm{C} / \mathrm{N}$ is an indicator which allows judging the level of the evolution of organic materials. We mean his aptitude to decompose in the soil. The soil microorganisms have the average $\mathrm{C} / \mathrm{N}$ of 8 . It consumes the $2 / 3$ of carbon for energy and $1 / 3$ for their constitution. The nitrogen is used almost for the constitution only. The nutritional balance of microorganisms is located to a $\mathrm{C} / \mathrm{N}$ of 24 . Under this ration, the nitrogen is in excess and will be therefore 
released to the availability of plants. More than that, the nitrogen will be taken from the soil to provide for the microorganisms needs. Then $\mathrm{C} / \mathrm{N}<15$ : the nitrogen production, the speed of decomposition is high; it is in maximum for a ratio $\mathrm{C} / \mathrm{N}=10 ; 15<\mathrm{C} / \mathrm{N}<20$ : the need of nitrogen is covered to allow a good decomposition carboneous material; $\mathrm{C} / \mathrm{N}>20$ : no more nitrogen for allowing the carbon decomposition. The nitrogen is now taken from the soil reserves. The mineralisation is slow and gives back to the soil a weak quantity of mineral nitrogen. It is agreed that the more the $\mathrm{C} / \mathrm{N}$ is higher, more it decompose slowly in the ground but the humus is stable (Giroux and Audesse, 2004). Likewise for us, this connection is high and exists for the animal and human wastes with the correlation respectively of 0.362 and 0.95 . It is however inexisting for the agricultural wastes with the correlation of 24 because this numeral doesn't belong in the space of -1 and 1 . The microbe generators of biogas need carbon 25 to 30 times more than nitrogen. Consequently, the optimal ratio of $\mathrm{C} / \mathrm{N}$ of raw materials is 25 to 30. Generally direct seeding into a compost is not recommended due to the speed with which it may dry and the possible presence of phytotoxins that may inhibit germination (Morel and Guillemain, 2004; Itavaara et al., 2000).

\section{CONCLUSION}

The organic materials which produce biogas contain many chemical elements among which the principals are: carbon $(\mathrm{C})$, hydrogen $(\mathrm{H})$, Nitrogen $(\mathrm{N})$, phosphore $(\mathrm{P})$ and sulfur $(\mathrm{S})$. The ratio Carbon/Nitrogen is an important power in evaluating the capacity of the materials to decompose. Generally, the microbe generators of biogas need carbon twenty five to thirty times more than nitrogen. The coefficient of correlation helped to measure the degree of relation between Nitrogen and carbon. The global objective was to detect the concentration of nitrogen and carbon, the determination of the ratio as well as their connection in the different types of wastes. The samples harvested, tested and studied in the laboratories have allowed easy observation on its concentration and existence or no connection after the correlation test. The Kjeldhal method and the statistic one have made it easy to harvest samples and detect the connection between the different types of wastes. The test for the animal and human wastes gave the correlation respectively of 0.362 and 0.95 . It showed however no correlation for the agricultural wastes with 24 , because this numeral wasn't in the space of -1 and 1 . The average $\mathrm{C} / \mathrm{N}$ ratio was 24 , 9 for first type and 74 for the second type of wastes. We can realize that in the first type of waste the correlation is weak and negative, in the second the correlation is strong and positive, and in the last there is no connection.

\section{REFERENCES}

M. Giroux et P. Audesse (2004) Comparaison de deux méthodes de détermination des teneurs en carbone organique, en azote totale et du rapport $\mathrm{C} / \mathrm{N}$ de divers amendements organiques et engrais de ferme, agrosol, Vol. 15, N².

Morel P. \& Guillemain G. (2004), Assessment of the possible phytotoxicity of a substrate using an easy and representative biotest. Acta Horticulture 644:417-423.

Dougherty, Mark (1999). Field guide to on-farm composting. Ithaca, New York; Natural resource, Agriculture and engineering service.

University of Minnesota (2011) Manure management and air quality, Manure. Umn.edu.

Bacquerel (A. Cesar, M.) (1865). Mémoire sur les forets et leur influence climatique, (exemplaire numérisé par Google), P.124.

Itavaara, (2000) Compost maturity-problems associated with testing, in proceedings of composting. Innsbruck Austria.

Beatriz Cordero, Verónica Gómez, Ana E. Platero-Prats, Marc Revés, Jorge Echeverría, Eduard Cremades, Flavia Barragán et Santiago Alvarez, (2008). Covalent radii revisited, Dalton Transactions, p. 2832 - 2838

W. M. Haynes, (2011). Ionization Energies of Atoms and Atomic lons," in CRC Handbook of Chemistry and Physics, ed., CRC Press/Taylor and Francis, Boca Raton, FL., p. 10-203

Greenwood N. \& Earnwhaw A. (2003). Chemistry of the elements, 2nde Ed. Elsevier, p.443.

David R. Lide, (2009). CRC Handbook of Chemistry and Physics, CRC Press Inc, , 90e éd., Relié, 2804 p.

Greenwood N. \& Earnwhaw A. (1994). Chemistry of the elements, N.N., Pergamon Press, P.356.

Paul Arnaud, Brigitte Jamart, Jacques Bodiguel, Nicolas Brosse, (2004). Chimie Organique 1er cycle/Licence, PCEM, Pharmacie, Cours, QCM et applications, Dunod, Broché, 710 p.

Cohen, J. (1988). Statistical power analysis for the behavioral sciences, Londres $\left(2^{\text {nd }} \mathrm{ed}\right.$.)

Michel, A. (2001). Le statut changeant de la corrélation en économétrie (1910-1944), Revue économique, Vol 52 n³, p.617-631.

BALUKU B., (1997). Distribution des mollusques dulcicoles, hôtes intermédiaires des schistosomes humains à Katana, Sud Kivu, RDCongo. Méd. Trop.57,4 ,370- 377.

National Program of Biogas of Burkina-Faso (NPB-BF), (2005). Manual Formation for domestic biodigester Builders. http://wikimedia.org/wiki/file:cycle_azote_fr.svg 
Cite this Article: Chanceline BM, Etienne MM, Godefroid KM, Soleil HS, 2014. The Study of the C/N Ratio in the Domestic Biogas Usable Wastes: A Case Study of Irhambi/Katana. Greener Journal of Environmental Management and Public Safety, 3, 2 , 026- 034. 